\title{
PENGEMBANGAN USAHA BENIH JAGUNG TAHAN KERING
}

\author{
S.M. Sarwadana ${ }^{1}$, B.R.T. Putri ${ }^{2}$ dan K.K. Dinata ${ }^{3}$
}

\begin{abstract}
ABSTRAK
Kegiatan Ipteks bagi inovasi dan kreativitas kampus bertujuan diantaranya: (1) komersialisasi Ipteks kreativitas kampus sebagai sumber pembiayaan untuk pengebangan institusi; (2) memacu jiwa kewirausahaan dikalangan insan kampus, dan (3) membantu masyarakat mendapatkan benih varietas jagung tahan kering. Metode pelaksanaan meliputi aspek bisnis rencana usaha kegiatan yang terdiri dari: bahan baku, produksi, proses produksi, manajemen, pemasaran, sumberdaya manusia, fasilitas, dan financial. Bahan baku diperoleh dari unit IbIKK dan melalui kemitraan dengan petani penangkar benih jagung. Proses produksi dimulai dari penagkaran benih, sortasi, dan packaging. Pemasaran dilakukan secara langsung, kemitraan dengan Pemda dan konsiniasi dengan kios/toko pertanian. Hasil kegiatan menunjukkan bahwa unit IbIKK benih jagung tahan kering telah berjalan dengan baik ditandai oleh dukungan sarana dan prasarana produksi benih jagung yang memadai; Unit IbIKK beroperasi dibawah manajemen PS Agroekoteknologi Fakultas Pertanian Universitas Udayana; Invenstasi yang dilakukan pada tahun 2014 sebesar Rp. 39,550,000; Omset penjualan yang diperolah pada tahun 2014 sebesar $400 \mathrm{~kg}$ (Rp. 12.000.000); dan arus kas bersih sebesar $17,672,400$.
\end{abstract}

Kata Kunci: benih jagung, tahan kekeringan, ipteks bagi inovasi dan kreativitas kampus.

\begin{abstract}
Activities of science and technology for innovation and creativity campus aims are: (1) the commercialization of science and technology campus creativity as a source of financing for the development of institutions; (2) stimulate the entrepreneurial spirit among beings campus, and (3) help people get seeds of drought-tolerant maize varieties. Methods of execution include the business aspects of the planned business activities consist of: provision of raw materials, production processes, management, marketing, human resources, facilities, and financial. The raw material is obtained from units of science and technology for novation and creativity campus and through partnerships with farmers' seed corn. The production process started from seed, sorting, and packaging. Marketing is done directly, partnerships with local governments and konsiniasi with kiosk / farm shop. Results show that the activities of science and technology unit for innovation and creativity campus drought-tolerant maize seed has gone well characterized by support infrastructure adequate maize seed production; IbIKK unit operates under the management of PS Agroecotechnology Faculty of Agriculture, University of Udayana; Of investment made in 2014 amounting to Rp. 39,550,000; Result of sales corn seeds turnover in 2014 amounted to $400 \mathrm{~kg}$ (Rp. 12 million); and net cash flow amounted to $17,672,400$.
\end{abstract}

Keywords: corn seeds, drought resistant, science and technology for innovation and creativity campus.

\footnotetext{
${ }^{1}$ Staf Pengajar Fakultas Pertanian,Universitas Udayana, sarwadana55@gmail.com

${ }^{2}$ Staf Pengajar Fakultas Peternakan Universitas Udayana, tanama_putri@yahoo.com

${ }^{3}$ Staf Pengajar Fakultas Pertanian Universitas Udayanana
} 


\section{PENDAhUluan}

Jagung mempunyai peran stragtegis dalam perekonomian nasional, mengingat fungsinya yang multiguna. Jagung dapat dimanfaatkan untuk pangan, pakan, dan bahan baku industri. Dari seluruh kebutuhan jagung, 50\% di antaranya digunakan untuk pakan. Dalam lima tahun terakhir, kebutuhan jagung untuk bahan baku industri pakan, makanan, dan minuman meningkat $10-15 \%$ per tahun. Luas areal pertanaman jagung di Indonesia sekitar 3,35 juta ha/tahun dengan laju peningkatan $0,95 \%$ per tahun. Data Kementrian Pertanian menunjukkan bahwa sekitar $79 \%$ areal pertanaman jagung terdapat di lahan kering, $11 \%$ terdapat di lahan sawah irigasi, dan $10 \%$ di sawah tadah hujan. Produktivitas jagung di Indonesia masih sangat rendah, baru mencapai 3,47 ton/ha pada tahun 2006, namun cenderung meningkat dengan laju 3,38\% per tahun.

Luas lahan yang potensial ditanami tanaman jagung di Propinsi Bali adalah 600.699 ha, 85,26 persen atau 480.559 hektar dari luas lahan tersebut adalah lahan kering. Dari luas sebanyak itu, 42,10 persen (202.335 hektar) berada di Bali Utara sedangkan sisanya terdapat di Kabupjagungn Karangasem dan Kecamatan Nusa Penida Kelungkung. Lahan kering tersebut tergolong lahan kering tipe D4 dengan bulan basah 3-4 bulan dan curah hujan berkisar $1200-1600 \mathrm{~mm} / \mathrm{tahun}$ (Suprapto dkk., 2000). Bali memproduksi jagung sebanyak 8.115 ton per tahuan, produksi ini diharapkan terus bertambah sesuai dengan meningkatnya kebutuhan pasar akan komoditas ini.

Dalam rangka memacu produksi jagung nasional dan Bali khususnya diperlukan benih varietas jagung yang tahan terhadap cekaman kekeringan, berumur pendek/genjah, potensi produksi cukup tinggi, serta pada saat panen biomasanya masih hijau (stay green) sehingga dapat dimanfaatkan sebagai pakan ternak (sapi). Dalam upaya menjawab persoalan tersebut, peneliti dari Universitas Udayana melalui penelitian kerjasama dengan Pemerintah Provinsi Bali dan Hibah bersaing Dikti, sejak tahun 2004 - 2010 telah merakit dan terus mengembangkan varietas jagung komposit lokal yang diberi nama "cicih tombong" . Nama Cicih tombong merupakan bahasa lokal Bali yang berarti "cicih = genjah, dan tombong = berwarna putih". Varietas ini dihasilkan dari hasil seleksi dan pemuliaan jagung yang toleran kekeringan di Kabupaten Buleleng bagian Barat.

Keunggulan dari varietas jagung ini, diantaranya: Tahan terhadap cekaman kekeringan; berumur genjah (70 hari) sehingga dapat ditanam $4 \mathrm{kali} /$ tahun; potensi produksinya cukup tinggi (sekitar 5 t/ha); Buah jagung muda terasa enak dan memiliki tekstur kenyal sehingga cocok dipanen muda untuk dijadikan jagung rebus sehingga saat panen biomasanya masih hijau (stay green) sehingga dapat dimanfaatkan sebagai pakan ternak (sapi) yang baik.

Varietas jagung "cicih tombong" merupakan varietas baru dan belum ada pihak lain yang menghasilkan varietas serupa. Oleh sebab itu, produk ini belum memiliki kompetitor di pasaran. Memperhatikan keunggulan yang dimiliki oleh varietas ini mendorong munculnya pemikiran menjadikan usaha penangkaran benih jagung tahan kekeringan sebagai Unit Ipteks bagi Inovasi dan Kreativitas Kampus. Produk benih ini memiliki peluang pasar yang sangat besar mengingat luas lahan kering di Indonesia cukup luas. Sebagai contoh untuk Propinsi Bali, potensi lahan untuk usaha tani jagung mencapai 480.559 hektar. Bila diasumsikan bahwa kebutuhan benih jagung per hektar rata-rata $30 \mathrm{~kg} / \mathrm{ha}$, maka benih yang diperlukan sebanyak $1.216,77$ ton per tahun. Kebutuhan ini masih jauh di bawah kebutuhan benih jagung untuk Propinsi NTB dan NTT yang memliki luas lahan kering yang sangat luas.

\section{METODE PELAKSANAAN}

Metode pelaksanaan meliputi aspek bisnis rencana usaha kegiatan, yang meliputi bahan baku, proses produksi, dan manajemen. Bahan baku dalam usaha ini berupa benih jagung sumber, bahan baku ini dihasilkan sendiri oleh unit IbIKK sehingga mutunya dapat terjaga. Benih Jagung 
diperoleh dari kebun koleksi PS Agroekoteknologi Fakultas Pertanian Universitas Udayana. Untuk memenuhi kebutuhn pasar yang semakin meningkat kebutuhan bahan baku diperoleh melalui kemitraan dengan petani penangkar benih jagung binaan IbIKK.

Proses produksi benih jagung dimulai dari penanaman sumber benih di lapangan, pemeliharaan tanaman melalui pemupukan dan penanggulangan hama dan penyakit, serta panen. Penanganan pasca panen merupakan bagian penting dari proses produksi benih jagung, pada tahapan ini dilakukan langkah-langkah sebagai berikut:

1) Seleksi tongkol (tongkol yang sesuai kriteria diproses lebih lanjut).

2) Penjemuran tongkol sampai kadar air biji mencapai 16\%,

3) dipipil dengan mesin pemipil benih

4) sortasi biji dengan menggunakan saringan/ayakan Ø $7 \mathrm{~mm}$

5) Uji daya kecambah benih

6) dikemas dalam wadah kemasan plastic diberi label (nama varietas, tanggal panen, kadar air benih, waktu dikemas, daya kecambah)

7) disimpan dalam gudang atau ruang berAC (agar benih dapat bertahan lama).

Kegiatan unit IbIKK dilakukan di Kebun milik Fakultas pertanian Universitas Udayana, Desa Pedungan, Kecamatan Denpasar Selatan, Kota Denpasar. Terdiri dari tiga bagian utama yaitu : kebun produksi, kantor, gedung prosesing benih, laboratorium, dan gudang penyimpanan. Layout fasilitas penunjang unit IbKK tersebut disajikan pada Gambar 3.
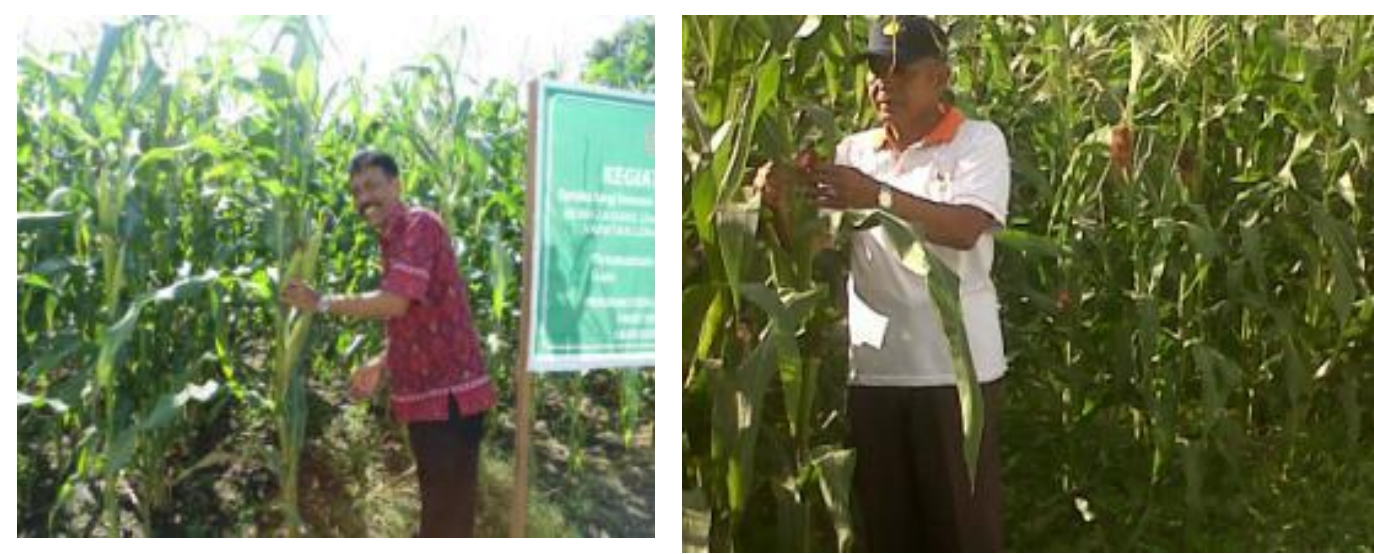

Gambar 1. Produksi Benih Jagung

Kualitas produk menjadi aspek yang sangat penting dalam usaha benih jagung. Ada tiga kriteria mutu benih yaitu : (a) kualitas genetik, yaitu kualitas benih yang ditentukan berdasarkan identitas genetik yang telah ditetapkanoleh pemulia; (b) kualitas fisiologi, yaitu kualitas benih yang ditentukan oleh daya berkecambah/daya tumbuh dan ketahanan simpan benih; (c) kualitas fisik, ditentukan oleh tingkat kebersihan, keseragaman biji baik dari segi ukuran ataupun bobot, adanya kontaminasi dari benih tanamanlain atau biji gulma serta tingkat kadar air. Untuk menjaga agar benih yang dipasarkan maka pada unit IbKK dilengkapi dengan bidang yang khusus menangani pengontrolan produk agar kualitas benih yang diproduksi selalu memenuhi standar kriteria yang berlaku.

$\mathrm{I}_{\mathrm{b}} \mathrm{IKK}$ Benih Jagung pengelolaannya berada di bawah Fakultas Pertanian Universitas Udayana. Sebagai unit usaha di bawah fakultas, kewajiban akan dipenuhi dalam kaitannya dengan NPWP, jaminan karyawan terkait dengan pajak penghasilan, pajak lainnya yang terkait dengan keberadaan kantor, dan sebagainya. Laporan pelaksanaan kegiatan dilakukan secara tertulis oleh ketua pelaksana kegiatan kepada penanggung jawab secara berkala setiap kuartal (empat bulanan). 
Laporan kuartal berupa aliran kas/casflow, sedangkan laporan tahunan dilengkapi dengan neraca aktiva-fasiva.

Pasar potensial yang menyerap produk IbIKK adalah petani jagung di Bali yang mencapai luasan 480.559 hektar. Bila diasumsikan, bahwa kebutuhan benih jagung per hektar rata-rata $30 \mathrm{~kg} / \mathrm{ha}$, maka benih yang diperlukan sebanyak 1.216, 77 ton per tahun. Selain itu, petani jagung lahan kering di wilayah Indonesia Timur seperti NTB dan NTT juga akan menjadi pasar potensial bagi produk IbIKK tersebut.

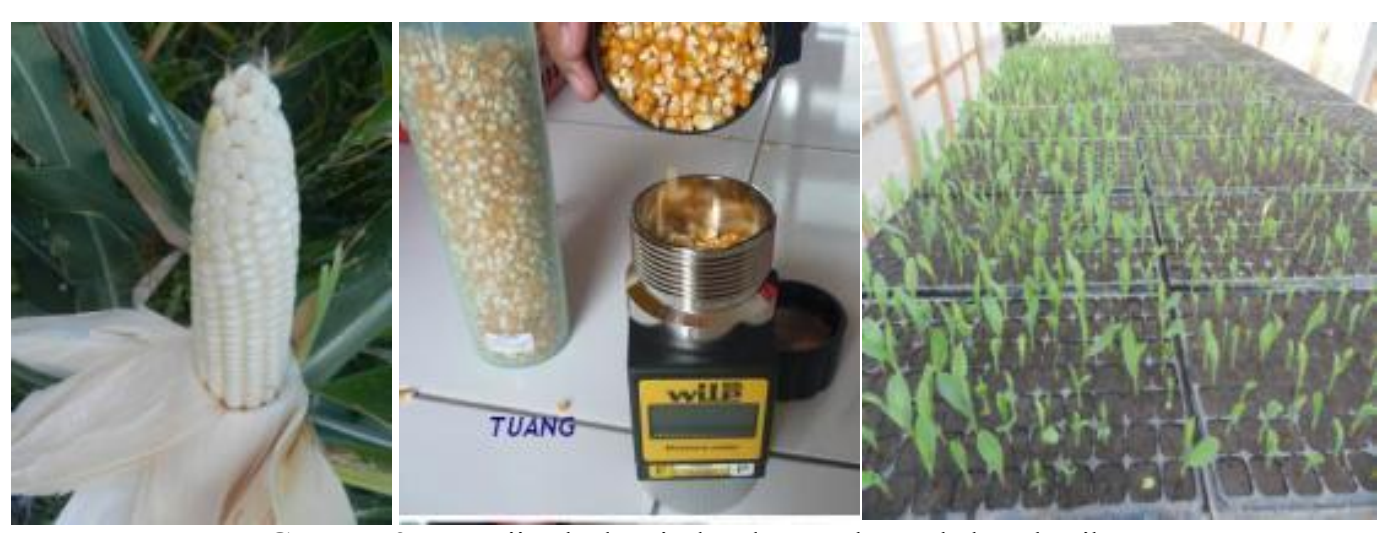

Gambar 2. Pengujian kadar air dan daya perkecambahan benih

\section{HASIL DAN PEMBAHASAN}

Produk utama yang dihasilkan pada $\mathrm{I}_{b} \mathrm{IKK}$ Benih Jagung adalah Benih jagung. Diambil dari varietas jagung lokal yang tahan kekeringan, selanjutnya diseleksi untuk menghasilkan benih jagung yang tahan kering tetapi ukuran tongkol yang lebih besar dan sifat-sifat unggul lainnya. Spesifikasi Produk adalah varietas jagung yang tahan terhadap cekaman kekeringan; berumur genjah (70 hari) sehingga dapat ditanam $4 \mathrm{kali} /$ tahun; potensi produksinya cukup tinggi (sekitar 5 t/ha) dan Organoleptik buah yang enak dengan tekstur kenyal cocok dikonsumsi muda yang berpeluang dijual dengan harga lebih mahal dibandingkan harga jagung pipilan; Biomasa jagung masih hijau (stay green) pada saat panen; mengaplikasikan teknik seleksi dan bredeeng jagung local lahan kering; kapasitas produksi $5.000-20.000 \mathrm{~kg}$ per tahun; Harga Rp. $30.000-40.000$,per kg.

Produk unit IbIKK berupa benih jagung tahan kekeringan. Dihasilkan melalui aplikasi teknologi seleksi dan breeding jenis jagung lokal yang tumbuh di daerah kering di Bali seperti Seraya Kabupaten Karangasem dan Gerokgak Kabupaten Buleleng. Unit $\mathrm{I}_{b} \mathrm{IKK}$ Benih Jagung memerlukan peralatan produksi dan laboratorium seperti : alat grading, freezer untuk penyimpanan benih induk, dan alat untuk mengukur kadar air. Ruang untuk penyimpanan benih, alat pemipil jagung, dan peralatan packaging. Pada tahun awal kegiatan IbIKK sebagian besar anggaran dialokasikan untuk investasi. Investasi tersebut meliputi rehabilitasi gudang dan pengadaan peralatan di laboratorium serta peralatan produksi benih lainnya. Sumberdaya investasi berasal dari pendanaan perguruan tinggi dan Dikti. Jumlah investasi pada tahun 2014 sebesar Rp. 39.550.000,

Kapasitas produksi unit IbIKK sampai saat ini adalah sebanyak $3000 \mathrm{~kg}$ benih jagung dalam satu tahun. Kapasitas produksi ini sangat ditentukan oleh luas lahan, permodalan dan gudang penyimpanan serta tenaga kerja yang terlibat dalam proses produksi. Keseluruhan produk Benih Jagung untuk tahun 2014 diperoleh melalui pemasaran berdasarkan pesanan, yaitu dari Dinas Pertanian Kabupaten Karangasem. Namun demikian, pemasaran juga dilakukan melalui 
konsinyiasi dengan perusahan penjual benih yaitu CV Widya Sari di Kabupaten Tabanan dan distributor benih Panah Merah wilayah Bali. Jumlah Benih yang sudah terjual mulai juli sampai Oktober 2014 adalah sebanyak $400 \mathrm{~kg}$ dari $3000 \mathrm{~kg}$ yang ditargetkan. Sisanya akan dipasarkan pada bulan Desember sampai Januari sesuai dengan kesiapan Benih jagung untuk ditanam. Harga penjualan adalah Rp. 30.000 - 40.000/ kg. Produk Benih jagung yang dipasarkan belum tersertifikasi, kualitas benih diukur dengan daya tumbuh/perkecambahan. Hasil pengujian daya kecambah benih mencapai 95\%.

Kontrol terhadap mutu dilakukan oleh bagian kontrol produk internal, yang sampai saat ini masih dirangkap oleh bagian produksi. Kontrol kualitas dilakukan sampling secara acak untuk diuji daya perkecambahannya. Persolan-persolan yang dijumpai dibahas pada laboratorium Pemuliaan Tanaman PS. Agroekoteknilogi. Ruangan yang disediakan bagi $\mathrm{I}_{\mathrm{b}} \mathrm{IKK}$ Benih Jagung saat ini adalah 2 ha lahan untuk produksi benih, satu ruang berukuran $4 \mathrm{~m} \times 6 \mathrm{~m}\left(24 \mathrm{~m}^{2}\right)$ untuk proses packaging, dan satu ruang berukuran $6 \mathrm{~m} \times 6 \mathrm{~m}$ untuk gudang penyimpanan benih. Kedepan apabila usaha ini telah berkembang diperlukan tambahan kapasitas ruang produksi dan gudang. Ruangan yang dijadikan tempat usaha $\mathrm{I}_{\mathrm{b}} \mathrm{IKK}$ Benih Jagung berlokasi di Kebun Percobaan Fakultas Pertanian Universitas Udayana. Gedung bersangkutan berada di bawah manajemen Fakultas Pertanian Universitas Udayana.

Unit Usaha Benih Jagung, dalam operasionalnya menjalin kerjasama dengan Kelompok Tani yaitu Kelompok Tani Desa Pangled dan Tenganan Karangasem, Wana Kerti di Baturiti, dan Gerokgak di Buleleng. Kejasama dibidang pemasaran dilakukan dengan CV. Setia Tani dan Widyasari di Kabupaten Tabanan, serta PT Panah Merah Cabang Bali. Dana operasional $\mathrm{I}_{\mathrm{b}} \mathrm{IKK}$ diprioritaskan untuk tujuan investasi sebanyak Rp. 39,550,000 dan sisanya untuk modal usaha. Strategi ini ditempuh untuk menyiapkan sarana penunjang produksi Benih Jagung yang memadai, untuk mengembangkan $\mathrm{I}_{b} \mathrm{IKK}$ menjadi unit usaha yang mandiri.

Jumlah produk Benih Jagung yang berhasil terjual adalah mencapai $400 \mathrm{~kg}$, capaian teresebut masih jauh di bawah proyeksi capaian semula yaitu sebanyak $2000 \mathrm{~kg}$. Omzet ini akan dapat dicapai pada bulan Desember 2014 - Januari 2015 mengingat saat ini masih musim kering panjang, sehingga tidak ada petani yang dapat menanam jagung. Benih tersebut merupakan pesanan dari Pemda Karangasem. Nilai nominal hasil penjualan Benih jagung tersebut sebanyak Rp. 12,000,000,-. Saldo tahunan yang diperoleh $\mathrm{I}_{b} \mathrm{IKK}$ pada tahun 2014 berjumlah Rp. 17.672.400. 
Cashflow ibikk benih jagung

\begin{tabular}{lr}
\hline & Uraian \\
\hline Aliran kas masuk & Total \\
Pendapatan bersih & $12,000,000$ \\
Bantuan dari dikti & $85,000,000$ \\
Bantuan dari unud & $20,000,000$ \\
Total aliran masuk & $117,000,000$ \\
& - \\
Aliran kas ke luar & - \\
a. Biaya tetap & $33,000,000$ \\
b. Biaya variabel & $20,814,000$ \\
c. Investasi & $39,550,000$ \\
Total pengeluaran & $97,364,000$ \\
Pendapatan kotor & $19,636,000$ \\
Pajak (10\%) & $1,963,600$ \\
Arus kas bersih & $17,672,400$ \\
& \\
Saldo awal & \\
Saldo akhir & $17,672,400$ \\
\hline
\end{tabular}

\section{KESIMPULAN DAN SARAN}

Berdasarkan hasil pelaksanaan program IbIKK benih jagung tahan kekeringan tersebut di atas, maka dapat disimpulkan sebagai berikut;

1) Unit IbIKK Benih Jagung Tahan kering beroperasi dibawah manajemen PS Agroekoteknologi Fakultas Pertanian Universitas Udayana.

2) Unit IbIKK Benih Jagung Tahan kering telah berjalan dengan baik ditandai oleh dukungan sarana dan prasarana produksi benih jagung yang memadai.

3) Invenstasi yang dilakukan pada tahun 2014 sebesar Rp. 39,550,000.

4) Omset penjualan yang diperoleh pada tahun 2014 sebesar $400 \mathrm{~kg}$ (Rp. 12.000.000) pesanan Pemda Karangasem.

5) Arus kas bersih sebesar 17,672,400.

\section{UCAPAN TERIMAKASIH}

Ucapan terima kasih dan penghargaan yang tinggi diberikan kepada Direktorat Riset dan Pengabdian Masyarakat Kemenristek Dikti atas dana yang diberikan, Rektor Universitas Udayana atas dana penyertaan atau pendampingan Program IbIKK dan Dekan Fakultas Pertanian atas fasilitas kebun untuk operasional unit IbIKK.

\section{DAFTAR PUSTAKA}

Balai Statistik Propinsi Bali. 2012. Bali dalam Angka 2012. Balai Statistik Propinsi Bali Renon. Denpasar. Muhammad Yasin. 2009. Upaya Penyediaan Benih Dasar Jagung Komposit Melalui Pembinaan Penangkar Benih Di Tingkat Petani. Prosiding Seminar Nasional Serealia 2009.

Sudarka Wayan, Sang Made Sarwadana, Ni Made Pradnyawati, I Gst. Ngurah Rakadan I Gst. Alit Gunadi. 2008. Perbaikan Karakter Agronomi Tanaman Jagung Varietas Lokal Cicih Tombong dengan Seleksi Massa yang Dimodifikasi 
Sudarka Wayan, Sang Made Sarwadana, Ni Made Pradnyawati, I Gst. Ngurah Raka dan I Gst. Alit Gunadi. 2009. Perbaikan Karakter Agronomi Tanama Jagung Varietas Lokal Cicih Tombong dengan Seleksi Massa yang Dimodifikasi

Sudarka Wayan, Sang Made Sarwadana, Ni Made Pradnyawati, I Gst. Ngurah Raka dan I Gst. Alit Gunadi. 2009 Upaya Pengembangan Varietas Jagung Tahan Kering melaluai Evaluasi Galur SMCT-2. BUMI LESTARI, Jurnal Lingkungan Hidup. 